\title{
Enfekte total kalça protezi tedavisinde çift aşamalı revizyon
}

\section{Two-stage revision of infected total hip arthroplasty}

\author{
Ömer Faruk Bilgen, Osman Yaray, Müren Mutlu
}

Özel Medicabil Hastanesi, Bursa

\begin{abstract}
Enfekte total kalça protezi tanı ve tedavisi zordur. Tanıda klinik bulgular, radyolojik bulgular ve laboratuvar bulguları bir bütün olarak değerlendirilmeli, bunun sonucuna göre hastaya en uygun tedavi planlanmalıdır. Literatürde debridman, tek aşamalı revizyon, çift aşamalı revizyon, antibiyotikle baskılama ve ampütasyon gibi birçok tedavi tanımlanmıştır; ancak üzerinde uzlaşılmış bir tedavi metodu bulunmamaktadır. Çift aşamalı revizyon ise, özellikle polimikrobiyal enfeksiyonlarda ve dirençli etkenlerde halen tedavide altın standart olarak kabul edilmektedir.
\end{abstract}

Anahtar sözcükler: total kalça protezi; protez çevresi eklem enfeksiyonu; revizyon cerrahisi
The diagnosis and treatment of infected total hip arthroplasty is challenging. Clinical, radiological and laboratory findings must be evaluated together and a patient-adapted treatment should be planned. Debridement, single-stage revision, two-stage revision, antibiotic suppression, and amputation were defined in literature; but there is no consensus on optimal treatment. Two-stage revision remains gold standard especially with resistant microorganisms and cases of polymicrobial infections.

Key words: total hip arthroplasty; periprosthetic joint infection; revision surgery

\section{SINIFLANDIRMA}

Illk cerrahiden sonra enfeksiyon bulgularının saptandığı zamana kadar geçen süre, tedavi planlamasında önemlidir. Filtzgerald ve ark. ${ }^{[10]}$ tarafindan yapılan sınıflandırma, Toms ve ark. ${ }^{[11]}$ tarafindan modifiye edilmiştir. Tsukayama ve ark. ${ }^{[12]}$ tarafından da dördüncü evre tanımlanmıştır (Tablo 1).

\section{TANI}

Enfekte TKP'de, stafilokok türleri en sık izole edilen mikroorganizmalardır. Ancak, izole edilen bakteri türü ve antibiyotik direnci bölgeden bölgeye farklılık gösterebilir. Bu da evrensel bir tedavi protokolü belirlemeyi zorlaştırmaktadır. Ülkelerin ulusal artroplasti kayıtlarına baktığımızda, koagülaz negatif stafilokok insidansı artmaktayken, gram negatif bakteri insidansı azalmaktadir (Tablo 2). ${ }^{[13]}$

Metisilin dirençli S.aureus (MDSA), metisilin dirençli S.epidermitis (MDSE) ve vankomisin dirençli enterokok

- İletişim adresi: Dr. Ömer Faruk Bilgen, Özel Medicabil Hastanesi Fethiye Mah. Küre Sok. No: 1, Nilüfer, Bursa Tel: 0224 - 6000300 e-posta: ofbilgen@gmail.com

- Geliștarihi: 1 Mart $2016 \quad$ Kabul tarihi: 1 Mart 2016 
Tablo 1. İlk cerrahiden enfeksiyon başlangıcına kadar geçen süreye göre periprostetik eklem enfeksiyonunun sınıflandırılması
Evre I
Illk cerrahiden sonraki altı hafta içinde görülen enfeksiyonlar (akut enfeksiyon).
Evre II Cerrahiden sonra geçen süreden bağımsız olarak kronik enfeksiyonun gecikmiş bulguları.
Evre III Fonksiyonel ağrısız bir kalçada ani başlayan enfeksiyon (genelde başka bir odaktan hematojen yolla başlar).
Evre IV Daha önceden enfeksiyon bulgusu olmayan hastalarda revizyon sırasında pozitif kültür.

Tablo 2. Sık görülen PEE organizmaların ülkelere göre bildirilmiş insidansları

\begin{tabular}{lcccc}
\hline Organizma & $\begin{array}{c}\text { Birleşik Krallıklar } \\
(\%)\end{array}$ & $\begin{array}{c}\text { Avustralya } \\
(\%)\end{array}$ & $\begin{array}{c}\text { Almanya } \\
(\%)\end{array}$ & $\begin{array}{c}\text { Birleşik Devletler } \\
(\%)\end{array}$ \\
\hline Metisiline duyarlı S.aureus & 44 & 30 & 13 & 31 \\
Koagülaz negatif S.aureus & 47 & 45 & 39,3 & 20,2 \\
Metisilin dirençli S.aureus & 8 & 45 & 48,1 & $-12,1$ \\
Polimikrobiyal enfeksiyon & 47 & 36 & - & - \\
Anaerobik organizmalar & 7 & 1,7 & 9,9 & 15,8
\end{tabular}

(VDE) gibi yüksek dirençli mikroorganizmaların tedavisi zordur. S.aureus türlerinin metisilin direnci \%30-35 iken sefalosporin direnci \%5'tir. S.epidermitis metisilin direnci \%30-41, enterokokların vankomisin direnci ise $\% 30$ olarak bildirilmiştir. ${ }^{[14-17]}$

Vücuttaki tüm yabancı cisimlerde olduğu gibi TKP'de de, kolonize olmuş mikroorganizmalar tarafından biyofilm tabakası oluşturulmaktadır. ${ }^{[18]}$ Biyofilm tabakası içindeki bakteriler organize bir yapı sergiler. ${ }^{[19]}$ İmplant üzerindeki biyofilm oluşumu dakikalar içinde başlayabilir. ${ }^{[20]}$ Bu biyofilm tabakası, glikokaliks matriksten meydana gelir ve bakteriler bu tabaka içinde durağan büyüme fazına girer, burada organize olup çok hücreli bir organizma gibi davranır. PEE tedavisinde biyofilm önemli bir sorun oluşturur. ilk olarak, hücresel savunma ve antibiyotik tedavisi yetersiz kalır. Bunun nedeni, biyofilmin bakteriyi fiziksel olarak korumasından ve biyofilm içindeki bakterinin yavaş çoğalmasından dolayı, antibiyotik etkinliğinin azalmasındandır. İkinci olarak da, biyofilm tabasından ayrılan parçacıkların çevre dokulara bakteriyi ekip enfeksiyonu yaymasıdır. ${ }^{[19-21]}$

PEE için, hiçbir test \%100 duyarlılık ve özgünlüğe sahip değildir (Tablo 3). Doğru tanı için, klinik şüphe, dikkatli fizik muayene, laboratuvar tetkikleri ve radyolojik tetkikler gerekir. Etkenin eklemden izole edilmesi "altın standart" değildir. Bunun yerine,
Kas-iskelet Sistemi Enfeksiyon Derneği (Musculoskeletal Infection Society) tarafından geliştirip ${ }^{[22]}$ PEE üzerine Uluslararası Konsensus Toplantısında (International Consensus Meeting) revize edilen ${ }^{[23]}$ ve Hastalık Kontrol Merkezi (Center for Diesase Control) ${ }^{[24]}$ tarafindan kabul edilen kriterlere göre PEE tanısı konmaktadır. Buna göre, aşağıdaki kriterlerden en az biri olmalıdır:

1- Periprostetik doku veya sıvılardan alınan iki farklı kültür aynı mikroorganizmanın izole edilmesi.

2- İmplantla ilişkisi olan sinus ağzı.

3- Aşağıdaki minör kriterlerden en az üçünün olması:

a- Serum C-reaktif protein (CRP) ve eritrosit sedimentasyon hızının (ESH) artması.

b- Sinoviyada beyaz kan hücreleri sayısının artması veya sinoviyal sıvı lökosit esteraz (LE) strip testinde ++ değişiklik.

c- Sinoviyal sıvıdaki polimorfonükleer nötrofil yüzdesinin artması (PMN).

d- Periprostetik dokunun histopatolojik incelenmesinde, en az beş alanda (400 kez büyütülmüş) beşten fazla $\mathrm{PMN}$ görülmesi.

e- Periprostetik doku veya sıvıdan alınan bir kültürde üreme olması.

Yukarda verilen kriterlerin alt sınırları Tablo 4'te özetlenmiştir. 
Tablo 3. PEE tanısında kullanılan testlerin duyarlılık ve özgünlük düzeyleri[25-31]

\begin{tabular}{lcc}
\hline Test & Duyarlılı (\%) & Özgünlük (\%) \\
\hline CRP & 96 & 92 \\
ESH & 82 & 56 \\
ESH ve CRP & 96 & $87-95$ \\
IL-6 & $95-100$ & 85 \\
Lökosit sayımı (sinoviyal sıvı) & 89 & 94 \\
Nötrofil sayımı (\%) (sinoviyal sıvı) & 80 & $89-100$ \\
IL-6 (sinoviyal sıvı) & 87 & $90-100$ \\
CRP (sinoviyal sıvı) & 97 & $95-100$ \\
Q-defensin (sinoviyal sıvı) & 100 & 86 \\
Kemik sintigrafisi & 33 & 88 \\
Lökosit işaretli sintigrafi & 77 & 94 \\
Kalça aspirasyonu & 86 & 98 \\
Gram boyama & 19 & 97 \\
Doku biyopsisi & 94 & 94 \\
Frozen inceleme & 80 & \\
\hline
\end{tabular}

CRP, C-reaktif protein; ESH, Eritrosit sedimentasyon hızı; IL-6, interlökin-6.

Tablo 4. PEE tanısında minör kriterlerin alt sınırları

\begin{tabular}{lll}
\hline & Akut & Kronik \\
\hline ESR & - & $>30 \mathrm{~mm} /$ saat \\
CRP & $>100 \mathrm{mg} / \mathrm{L}$ & $>10 \mathrm{mg} / \mathrm{L}$ \\
Sinoviya lökosit & $>10000$ hücre $/ \mu \mathrm{L}$ & $>3000$ hücre $/ \mu \mathrm{L}$ \\
Sinoviya PMN & $>\% 90$ & $>\% 80$ \\
Sinoviya LE & ++ & ++
\end{tabular}

PEE tanısı için biyomarkırlar üzerinde çalışmalar devam etmektedir. Lökosit esteraz (LE), enfeksiyon durumunda aktive nötrofillerden salgılanan bir enzimdir. Sinoviyal sıviya uygulanan basit idrar strip testi ile LE düzeyi belirlenebilir. Eğer sonuç $(++)$ ise, test müspettir. Bu durum sinoviyal lökosit sayımına eşit kabul edilir ve minör kriterler arasındadır. LE testi basit, ucuz, hızlı ve etkili bir testtir. ESH, CRP, sinoviya WBC sayımı, sinoviya PMN \% ile LE arasında yüksek korelasyon vardır. ${ }^{[32]}$ Üzerinde çalışılan bir başka biyomarkır ise, alfa defensindir ( $\alpha$-defensin). Sinoviyal sıvıdaki nötrofillerden salgılanan $\alpha$-defensin, patojen organizmanın hücre duvarına yapışarak antimikrobiyal etki gösterir. İmmünoassay testi ile sinoviyal sıvıdaki düzeyi belirlenir ve $5,2 \mathrm{mg} / \mathrm{L}$ üzerindeki düzeyler pozitif kabul edilir. Test sonuçları, antibiyotik tedavisinden veya sistemik inflamatuvar hastalıklardan etkilenmez. Duyarlılığ ve özgünlügü \%100'e yakındır. Sinoviyal CRP ile birlikte PEE tanısı için, $\alpha$-defensinin gelecekte önemli bir markır olacağı düşünülmektedir. ${ }^{[25]}$

\section{TEDAVi}

Kalça protezi sonrası oluşan PEE tedavi seçenekleri arasında; antibiyotik baskılaması, cerrahi debridman, tek aşamalı revizyon, çift aşamalı revizyon ve rezeksiyon artroplastisi/ampütasyon sayılabilir.

\section{Antibiyotik Baskılaması}

Cerrahi yapılmadan sadece antibiyotik ile enfeksiyonu baskılama, ancak yandaş hastalıklardan dolayı cerrahi yapılamayan hastalarda, cerrahi tedaviyi kabul etmeyen hastalarda, cerrahinin teknik olarak mümkün olmadığı durumlarda ve ağızdan alınacak toksik olmayan antibiyotik ile enfeksiyonun baskılanabileceği durumlarda uygulanabilir. ${ }^{[33-34]}$ Burada amaç, enfeksiyonun eradikasyonu değil baskılanmasıdır. ${ }^{[11]}$ Her ne kadar medikal tedavi ile enfeksiyon baskılansa ve hastaların ağrılarında gerileme görülse de, uzun dönemde fonksiyonel durumlar, revizyon cerrahisi yapılan hastalara göre daha kötüdür. ${ }^{[35-37]}$ 


\section{Debridman ve İmplantların Korunması}

TKP sonra akut başlayan PEE'de debridman yapılıp implantların korunması, sadece mobil parçaların değiştirilmesi için, birçok koşulun beraber sağlanması gerekir. Öncelikle enfeksiyon akut başlamalıdır (Evre I veya Evre III), implantlar stabil olmalıdır, yumuşak doku bütünlüğünün bozulmamış olması gerekir ve etken olan mikroorganizmanın biyofilme geçen antibiyotiklere (rifampisin, siprofloksisin, fosfomisin) karşı dirençli olmaması gerekir. ${ }^{[3,38]}$ Tedavide, artrotomiden sonra, geniş sinoviyektomi, radikal debridman, irrigasyon ve mobil parçaların değişimi yapılır. Tekrar enfeksiyon oranı, tecrübeli ellerde bile $\% 18^{[29]} \% 2{ }^{[31]}$ ve $\% 74^{[12]}$ olarak bildirilmiştir. Özellikle etkenin antibiyotik direnci fazla ise, tekrar enfeksiyon riski de çok fazladır. ${ }^{[39]}$

\section{Tek Aşamalı Revizyon}

Son zamanlarda, tedavi maliyetlerini düşürdüğü, fonksiyonel sonuçların daha iyi olduğu ve hasta memnuniyeti fazla olduğu için, tek aşamalı revizyon cerrahisine ilgi, özellikle Avrupa'da giderek artmaktadır. Başarı oranının \%75-100 arasında olduğunu bildiren birçok çalışma vardır. ${ }^{[0-44]}$ Ancak, önceden iki kez tek aşamalı revizyon yapılmış ve nüks olmuşsa, hastada sistemik sepsis semptomları varsa, etken mikroorganizma izole edilememişse, polimikrobiyal ve/veya MRSA gibi yüksek dirençli enfeksiyon, hastada ciddi yumuşak doku bozukluğu varsa, kontrendikedir.

Cerrahide, kalçadaki tüm protez materyalleri çıkarilır. Enfekte yumuşak dokular temizlendikten sonra, yeniden implantasyon yapılır. ${ }^{[33]}$ Ameliyat esnasında yeniden kültür alınıp çıkarılan implantlar, sonikasyona gönderilir. Antibiyotik tedavisine üç ay devam edilir.

\section{Çift Aşamalı Revizyon}

Çift aşamalı revizyon Kuzey Amerika ve başka birçok merkezde PEE tedavisi için en etkili metod ve altın standart olarak kabul edilmektedir. ${ }^{[45]}$ Başarı oranı \%88-96 iken, 12 yıllık takipte antibiyotik yüklü çimento spacer (Prosthesis of Antibiotic Loaded Acrylic Cement -PROSTALAC) ile uzun dönem başarı oranı \%90'dır. ${ }^{[46]}$ Cerrahide tüm implantlar çıkarılır, enfekte dokular debride edilir, kültür alınır, antibiyotik yüklü spacer konur. Altı-on iki hafta sonra ikinci aşamaya geçilip, yeniden implantasyon yapılır. Aradaki bekleme süresinde, hastaya genelde altı hafta antibiyotik tedavisi uygulanır. Antibiyotik tedavisi sonunda, iki hafta antibiyotik verilmeden hasta izlenir, CRP ve ESR düzeylerine bakılır. Eğer inflamatuvar markırlar yüksek ve hastada enfeksiyon bulgusu varsa, ponksiyon yapılabilir. İdeal bekleme süresi 10-12 haftadır.
Antibiyotik tedavisinin süresi hakkında tartışmalar devam etmektedir. Uzun dönem ve kısa dönem antibiyotik tedavisinin farklı olmadığını söyleyen çalışmalar varken $^{[46,47]}$, birçok çalışmada birinci ve ikinci aşama arasında altı hafta parenteral antibiyotik tedavisinin devam edilmesi gerektiği bildirilmiştir. ${ }^{[6]}$

ìki aşamalı revizyonda, yumuşak doku bozukluğu, hastada cerrahilere bağlı daha fazla fonksiyonel kayıp olması ve uzun dönem verilen antibiyotiklerin toksisitesine bağlı mortalite ve morbidite daha fazla görülür. [48-50] Ancak bu durum, hastaların yandaş hastalıklarına ve daha kompleks enfeksiyonla yapılan mücadeleye de bağlı olabilir.

Hastalarda, birinci aşmada debridman yapıldıktan sonra antibiyotikli spacer'lar kullanılır. Böylece, aşırı skar dokusunun oluşumu engellenir, ekstremite uzunluğu, eklem stabilitesi ve yumuşak doku dengesi sağlanır. Bunun yanı sıra, erken mobilizasyona izin verdiğinden ve rehabilitasyonu daha kolay olduğundan, hasta memnuniyeti de fazla fazladır. Ayrıca, ikinci aşamada cerrahi yaklaşım daha rahat olur. Genel pratikte, spacer'larda yüksek doz antibiyotik bulunur ve böylece intravenöz yolla verilemeyecek kadar yüksek dozda bir konsantrasyon sağlar. Eklemleşmeyen (statik) ve eklem yapan (dinamik) olmak üzere iki tip spacer vardır. Statik tipte eklem hareketi olmaz; buna bağlı kemik kaybı, kas atrofisi, artrofibrozis gelişir. ${ }^{[51]}$ Bunun yanı sıra, dinamik spacer'lar eklem hareketine izin verir; böylece daha az kemik kaybı ve skar oluşumu gerçekleşir, ikinci aşama cerrahi kolaylaşır. ${ }^{\left[{ }^{[1,52]}\right.}$ Dinamik spacer'larda hasta memnuniyeti daha fazladır, ancak kırılma ve dislokasyon gibi komplikasyonlara neden olabilir. Dinamik spacer'ların, hazır olanlar ve ameliyat esnasında hazırlanmanlar olarak iki tipi vardır. Çimentodaki antibiyotik konsantrasyonu yüksektir (paket başına $>1 \mathrm{gr}$ ). ${ }^{[53]}$ Vankomisin, teikoplanin ve gentamin veya tobramisin kullanılır.

İkinci aşama cerrahinin ne zaman yapılacağı, ayrı bir tartışma konusudur. Tekrar implantasyon için, laboratuvar bulgularının, radyolojik ve klinik bulguların düzelmiş olması gerekir. Antibiyotik tedavisi sırasında ESH ve CRP haftalık olarak izlenmeli, kademeli olarak düştüğü ve normal değerlere döndüğü görülmelidir. Ancak, inflamatuvar markırlar enfeksiyonun eradikasyonunu tespitte yetersiz kalabilir. ${ }^{[54]}$ Yara yerinin kuru ve hiperemik olmaması da önemli bir faktördür. Tedavi sonunda iki hafta antibiyotik verilmeden beklenip, $E R H$ ve CRP düzeylerinin normal değerlerde kaldığı teyit edilir. Bu aşamadan sonra, ikinci aşama planlanabilir. Eğer CRP yüksek devam ediyorsa, enfeksiyon dışındaki nedenler araştırılmalıdır. Genelde, yüksek CRP'nin nedeni inflamatuvar artrittir. Eğer hastanın kalçasında ağrı yoksa ve CRP yüksekliğinin enfeksiyona 
bağlı olmadığı düşünülüyorsa, hastaya uygun tedavi verilmeli ve ikinci aşamaya CRP normale döndükten sonra geçilmelidir. Tedaviye rağmen CRP yüksekliği devam ediyorsa, altı hafta daha antibiyotik tedavisi uygulanmalıdır. Eğer bu ikinci altı hafta sonunda da CRP normale gelmezse veya enfeksiyon bulguları mevcutsa, hastada birinci aşama tekrar yapılır. Yine bulgular düzelmezse veya tedavi edilemeyen dirençli bir enfeksiyon varlığında, spacer'lar çıkarılıp Girdlestone artroplastisi yapılır. İkinci aşamada hastanın spacer'ları çıkarılıp, genelde çimentosuz revizyon TKP uygulanır. Eğer hastada makroskopik olarak enfeksiyon bulguları mevcutsa, birinci aşama tekrarlanmalıdır. Hastanın doku ve sıvı kültürleri alınır, çıkarılan spacer'lar da kültüre ve sonikasyona gönderilir. İkinci aşamadan sonra kültürler negatifse, oral antibiyotiğe geçilir; eğer kültürlerde üreme olursa, intravenöz antibiyotik tedavisine devam edilmelidir.

\section{TARTIŞMA}

Kalça PEE tedavisinde birçok metod tanımlanmıştır. Her hasta ve her enfekte TKP farklı olduğundan, hastaya uygun tedavinin belirlenip uygulanması gerekir. Tedavinin en önemli kısmı, enfekte dokuların uygun şekilde debride edilmesi ve etkenin izole edilip enfeksiyon hastalıkları uzmanı tarafından uygun tedaviye başlanmasıdır. Debridman yeterli olmazsa, enfeksiyon eradikasyonu sağlanamaz. ${ }^{[55]}$ Akut başlangıçlı enfeksiyonlarda, komponentler stabil ise debridman yapılabilir. Etken izole edilmiş ve hastanın yumuşak doku sorunu yoksa, tek aşamalı revizyon planlanabilir.

Çift aşamalı revizyon, kalça PEE tedavisinde altın standarttır. Oussedik ve ark. ${ }^{[56]}$ yaptıkları çalışmada, 52 hastanın 12'sine tek aşamalı revizyon, geri kalan 39'una çift aşamalı revizyon yapmışlardır; tek aşamalı revizyon yapılan hastalarda tekrar enfeksiyon görülmezken, çift aşamalı revizyon yapılan hastaların ikisinde tekrar enfeksiyon gözlenmiştir. Fonksiyonel sonuçlar ve hasta memnuniyeti, tek aşamalı grupta anlamlı olarak fazla bulunmuştur. Ancak, çift aşamaI grupta hastalar ya daha virülan etkenlerle enfekte olmuşlar veya polimikrobiyal enfeksiyonlar görülmüş. $\mathrm{Bu}$ çalışmada iki grup eş değer olmadığı için, birbiri ile karşılaştırılamaz ve kesin bir sonuç çıkarmak mümkün değildir. Son zamanlarda bu konu ile ilgili iki derleme yayımlanmıştır. Beswick ve ark. ${ }^{[57]}$ tek aşamalı revizyon ile tedavi edilen 1225 hastanın \%8,6'sında tekrar enfeksiyon saptamışken, çift aşamalı revizyon yapılan 1188 hastanın \%10,2'sinde tekrar enfeksiyon görülmüştür. Diğer derlemede ise, Leonar ve ark.. ${ }^{[58]}$ enfeksiyon eradikasyonunu ve fonksiyonel sonuçları değerlendirmiş, enfeksiyon tekrarlama oranını, tek aşama ve çift aşamalı revizyonlarda, sırayla \%16,8 ve \%10,6 bulmuştur. Her iki grupta da fonksiyonel açıdan anlamlı fark saptamamıştır. Her iki çalışmada da, yazarlar, çalışmaların genel kalitesinin düşük olduğunu, randomizasyon yapılmadığını, tanımların ve metodolojinin farklılıklarından dolayı sonuçları karşılaştırmanın zor olduğunu belirtmişlerdir. Ayrıca, çalışmaların çok azında klinik sonuçların değerlendirilmesi yapılmıştır. Engesæeter ve ark. ${ }^{[59]}$ Norveç artroplasti kayıtlarına dayanarak yaptıkları çalışmada, tek aşamalı revizyon ile tedavi edilen hastalardaki tekrar revizyonun rölatif riskini, çift aşama revizyon ile tedavi edilen hastalarla karşılaştırmışlardır. Buna göre, herhangi bir nedenden dolayı revizyon riski 1,4 kat fazla, enfeksiyondan dolayı revizyon riski ise iki kat fazla bulunmuştur.

Sonuç olarak, PEE'de ideal bir tedavi üzerinde uzlaşılamamıştır. Tek aşamalı revizyon, belirtilen kriterlere uyan seçilmiş hasta grubunda uygulanabilir, ancak bunun da uzun dönem sonuçları bilinmemektedir. Çift aşamalı revizyon, günümüzde en sık tercih edilen tedavidir. Dinamik spacer kullanılarak yapılan revizyonlarda, uzun dönemde fonksiyonel sonuçların iyi ve enfeksiyon eradikasyonunun başarılı olduğunu gösteren çalışmalar vardır. Özellikle polimikrobiyal enfeksiyonlarda, dirençli etkenlerde, tek aşamalı revizyonun kontrendike olduğu durumlarda, çift aşamalı revizyon seçilecek tek tedavidir.

\section{KAYNAKLAR}

1. Campoccia D, Montanaro L, Arciola CR. The significance of infection related to orthopedic devices and issues of antibiotic resistance. Biomaterials 2006;27(11):2331-9.

2. Kurtz S, Ong K, Lau E, Mowat F, Halpern M. Projections of primary and revision hip and knee arthroplasty in the United States from 2005 to 2030. J Bone Joint Surg Am 2007;89(4):780-5.

3. Widmer AF. New developments in diagnosis and treatment of infection in orthopedic implants. Clin Infect Dis 2001;33 Suppl 2:S94-106.

4. Bozic KJ, Kurtz SM, Lau E, Ong K, Vail TP, Berry DJ. The epidemiology of revision total hip arthroplasty in the United States. J Bone Joint Surg Am 2009;91(1):128-33. Crossref

5. Jafari SM, Coyle C, Mortazavi SJ, Sharkey PF, Parvizi J. Revision hip arthroplasty: infection is the most common cause of failure. Clin Orthop Relat Res 2010;468(8):204651. doi: 10.1007/s11999-010-1251-6

6. Sandiford NA, Duncan CP, Garbuz DS, Masri BA. Two-stage management of the infected total hip arthroplasty. Hip Int 2015;25(4):308-15. Crossref

7. Sculco TP. The economic impact of infected total joint arthroplasty. Instr Course Lect 1992;42:349-51.

8. Kurtz SM, Lau E, Schmier J, Ong KL, Zhao KE, Parvizi J. Infection burden for hip and knee arthroplasty in the United States. J Arthroplasty 2008;23(7):984-91. Crossref

9. Bozic KJ, Ries MD. The impact of infection after total hip arthroplasty on hospital and surgeon resource utilization. J Bone Joint Surg Am 2005;87(8):1746-51. 
10. Fitzgerald RH, Nolan DR, Ilstrup DM, van Scoy RE, Washington $\mathrm{J}$, Coventry MB. Deep wound sepsis following total hip arthroplasty. J Bone Joint Surg Am 1977;59(7):847-55.

11. Toms AD, Davidson D, Masri BA, Duncan CP. The management of peri-prosthetic infection in total joint arthroplasty. J Bone Joint Surg Br 2006;88(2):149-55.

12. Tsukayama DT, Estrada R, Gustilo RB. Infection after total hip arthroplasty. A study of the treatment of one hundred and six infections. J Bone Joint Surg Am 1996;78(4):512-23.

13. Masterson EL, Masri BA, Duncan CP. Treatment of infection at the site of total hip replacement. Instr Course Lect 1998;47:297-306.

14. Garvin KL, Hinrichs SH, Urban JA. Emerging antibioticresistant bacteria: their treatment in total joint arthroplasty. Clin Orthop Relat Res 1999;(369):110-23.

15. Olson R, Donnenfeld E, Bucci FA Jr, Price FW Jr, Raizman M, Solomon K, Devgan U, Trattler W, Dell S, Wallace RB, Callegan M, Brown H, McDonnell PJ, Conway T, Schiffman RM, Hollander DA. Methicillin resistance of Staphylococcus species among health care and nonhealth care workers undergoing cataract surgery. Clin Ophthalmol 2010;4:150514. Crossref

16. James PJ, Butcher IA, Gardner ER, Hamblen DL. Methicillinresistant Staphylococcus epidermidis in infection of hip arthroplasties. J Bone Joint Surg Br 1994;76(5):725-7.

17. Toulson C, Walcott-Sapp S, Hur J, Salvati E, Bostrom M, Brause B, Westrich GH. Treatment of infected total hip arthroplasty with a 2-stage reimplantation protocol: update on "our institution's" experience from 1989 to 2003. J Arthroplasty 2009;24(7):1051-60. Crossref

18. Trampuz A, Zimmerli W. Prosthetic joint infections: update in diagnosis and treatment. Swiss Med Wkly 2005;135(17-18):243-51.

19. Davies D. Understanding biofilm resistance to antibacterial agents. Nat Rev Drug Discov 2003;2(2):114-22.

20. Gristina AG. Biomaterial-centered infection: microbial adhesion versus tissue integration. Science 1987;237(4822):1588-95.

21. Stewart PS, Costerton JW. Antibiotic resistance of bacteria in biofilms. Lancet 2001;358(9276):135-8.

22. Parvizi J, Zmistowski B, Berbari EF, Bauer TW, Springer BD, Della Valle CJ, Garvin KL, Mont MA, Wongworawat MD, Zalavras CG. New definition for periprosthetic joint infection: from the Workgroup of the Musculoskeletal Infection Society. Clin Orthop Relat Res 2011;469(11):2992-4. Crossref

23. Zmistowski B, Della Valle C, Bauer TW, Malizos KN, Alavi A, Bedair H, Booth RE, Choong P, Deirmengian C, Ehrlich GD, Gambir A, Huang R, Kissin Y, Kobayashi H, Kobayashi N, Krenn V, Drago L, Marston SB, Meermans G, Perez J, Ploegmakers JJ, Rosenberg A, Simpendorfer C, Thomas P, Tohtz S, Villafuerte JA, Wahl P, Wagenaar FC, Witzo E. Diagnosis of periprosthetic joint infection. J Arthroplasty 2014;29(2 Suppl):77-83. Crossref

24. Enayatollahi MA, Parvizi J. Diagnosis of infected total hip arthroplasty. Hip Int 2015;25(4):294-300. Crossref

25. Deirmengian C, Kardos K, Kilmartin P, Cameron A, Schiller $\mathrm{K}$, Parvizi J. Combined measurement of synovial fluid $\bigotimes$-defensin and C-reactive protein levels: highly accurate for diagnosing periprosthetic joint infection. J Bone Joint Surg Am 2014;96(17):1439-45. Crossref

26. Spangehl MJ, Masri BA, O'Connell JX, Duncan CP. Prospective analysis of preoperative and intraoperative investigations for the diagnosis of infection at the sites of two hundred and two revision total hip arthroplasties. J Bone Joint Surg Am 1999;81(5):672-83.
27. Austin MS, Ghanem E, Joshi A, Lindsay A, Parvizi J. A simple, cost-effective screening protocol to rule out periprosthetic infection. J Arthroplasty 2008;23(1):65-8. Crossref

28. Di Cesare PE, Chang E, Preston CF, Liu CJ. Serum interleukin-6 as a marker of periprosthetic infection following total hip and knee arthroplasty. J Bone Joint Surg Am 2005;87(9):1921-7.

29. Levitsky KA, Hozack WJ, Balderston RA, Rothman RH, Gluckman SJ, Maslack MM, Booth RE Jr. Evaluation of the painful prosthetic joint: relative value of bone scan, sedimentation rate, and joint aspiration. J Arthroplasty 1991;6(3):237-44.

30. Scher DM, Pak K, Lonner JH, Finkel JE, Zuckerman JD, Di Cesare PE. The predictive value of indium-III leukocyte scans in the diagnosis of infected total hip, knee, or resection arthroplasties. J Arthroplasty 2000;15(3):295-300.

31. Pill SG, Parvizi J, Tang PH, Garino JP, Nelson C, Zhuang H, Alavi A. Comparison of fluorodeoxyglucose positron emission tomography and (111)indium-white blood cell imaging in the diagnosis of periprosthetic infection of the hip. J Arthroplasty 2006;21(6 Suppl 2):91-7.

32. Parvizi J, Adeli B, Zmistowski B, Restrepo C, Greenwald AS. Management of periprosthetic joint infection: the current knowledge. J Bone Joint Surg Am 2012;94(14):e104. Crossref

33. Zimmerli W, Trampuz A, Ochsner PE. Prosthetic-joint infections. N Engl J Med 2004;351(16):1645-54.

34. Moran E, Byren I, Atkins BL. The diagnosis and management of prosthetic joint infections. J Antimicrob Chemother 2010;65 Suppl 3:iii45-54. Crossref

35. Bourne RH, Hunter GA, Rorabeck $\mathrm{CH}$, Macnab JJ. A sixyear follow-up of infected total hip replacements managed by Girdlestone's arthroplasty. J Bone Joint Surg $\mathrm{Br}$ 1984;66(3):340-3.

36. Castellanos J, Flores X, Llusa M, Chiriboga C, Navarro A. The Girdlestone pseudarthrosis in the treatment of infected hip replacements. Int Orthop 1998;22(3):178-81.

37. Byren I, Bejon P, Atkins BL, Angus B, Masters S, McLardySmith $P$, Gundle R, Berendt $A$. One hundred and twelve infected arthroplasties treated with 'DAIR'(debridement, antibiotics and implant retention): antibiotic duration and outcome. J Antimicrob Chemother 2009;63(6):1264-71. Crossref

38. Buller LT, Sabry FY, Easton RW, Klika AK, Barsoum WK. The preoperative prediction of success following irrigation and debridement with polyethylene exchange for hip and knee prosthetic joint infections. J Arthroplasty 2012;27(6):85764. Crossref

39. Crockarell JR, Hanssen AD, Osmon DR, Morrey BF. Treatment of Infection with Débridement and Retention of the Components following Hip Arthroplasty. J Bone Joint Surg Am 1998;80(9):1306-13.

40. Carlsson AS, Josefsson G, Lindberg L. Revision with gentamicin-impregnated cement for deep infections in total hip arthroplasties.J Bone Joint Surg Am 1978;60(8):1059-64.

41. Buchholz HW, Elson RA, Engelbrecht E, Lodenkamper $H$, Röttger J, Siegel A. Management of deep infection of total hip replacement. J Bone Joint Surg Br 1981;63(3):342-53.

42. Callaghan JJ, Katz RP, Johnston RC. One-stage revision surgery of the infected hip. A minimum 10-year followup study. Clin Orthop Relat Res 1999;(369):139-43.

43. Ure KJ, Amstutz HC, Nasser S, Schmalzried TP. Directexchange arthroplasty for the treatment of infection after total hip replacement. An average ten-year follow-up. J Bone Joint Surg Am 1998;80(7):961-8. 
44. Chen AF, Heller S, Parvizi J. Prosthetic joint infections. Surg Clin North Am 2014;94(6):1265-81. Crossref

45. Hanssen AD. Local antibiotic delivery vehicles in the treatment of musculoskeletal infection. Clin Orthop Relat Res 2005;(437):91-6.

46. Stockley I, Mockford BJ, Hoad-Reddick A, Norman P. The use of two-stage exchange arthroplasty with depot antibiotics in the absence of long-term antibiotic therapy in infected total hip replacement. J Bone Joint Surg Br 2008;90(2):145-8. Crossref

47. Hsieh PH, Huang KC, Lee PC, Lee MS. Two-stage revision of infected hip arthroplasty using an antibiotic-loaded spacer: retrospective comparison between short-term and prolonged antibiotic therapy. J Antimicrob Chemother 2009;64(2):3927. Crossref

48. Berend KR, Lombardi AV Jr, Morris MJ, Bergeson AG, Adams $\mathrm{JB}$, Sneller MA. Two-stage treatment of hip periprosthetic joint infection is associated with a high rate of infection control but high mortality. Clin Orthop Relat Res 2013;471(2):5108. Crossref

49. Langlais F. Can we improve the results of revision arthroplasty for infected total hip replacement? J Bone Joint Surg $\mathrm{Br}$ 2003;85(5):637-40

50. Luu A, Syed F, Raman G, Bhalla A, Muldoon E, Hadley S, Smith E, Rao M. Two-stage arthroplasty for prosthetic joint infection: a systematic review of acute kidney injury, systemic toxicity and infection control. J Arthroplasty 2013;28(9):1490-8.e1. Crossref

51. Cui Q, Mihalko WM, Shields JS, Ries M, Saleh KJ. Antibioticimpregnated cement spacers for the treatment of infection associated with total hip or knee arthroplasty. J Bone Joint Surg Am 2007;89(4):871-82.
52. Meek RD, Masri BA, Dunlop D, Garbuz DS, Greidanus NV, McGraw R, Duncan CP. Patient satisfaction and functional status after treatment of infection at the site of a total knee arthroplasty with use of the PROSTALAC articulating spacer. J Bone Joint Surg Am 2003;85-A(10):1888-92.

53. Hanssen AD, Spangehl MJ. Practical applications of antibiotic-loaded bone cement for treatment of infected joint replacements. Clin Orthop Relat Res 2004;(427):79-85.

54. Ghanem E, Azzam K, Seeley M, Joshi A, Parvizi J. Staged revision for knee arthroplasty infection: what is the role of serologic tests before reimplantation? Clin Orthop Relat Res 2009;467(7):1699-705. Crossref

55. Baker RP, Furustrand Tafin U, Borens O. Patient-adapted treatment for prosthetic hip joint infection. Hip Int 2015;25(4):316-22. Crossref

56. Oussedik SI, Dodd MB, Haddad FS. Outcomes of revision total hip replacement for infection after grading according to a standard protocol. J Bone Joint Surg Br 2010;92(9):12226. Crossref

57. Beswick AD, Elvers KT, Smith AJ, Gooberman-Hill R, Lovering A, Blom AW. What is the evidence base to guide surgical treatment of infected hip prostheses? Systematic review of longitudinal studies in unselected patients. BMC Med 2012;10:18

58. Leonard HA, Liddle AD, Burke O, Murray DW, Pandit $\mathrm{H}$. Single-or two-stage revision for infected total hip arthroplasty? A systematic review of the literature. Clin Orthop Relat Res 2014;472(3):1036-42. Crossref

59. Engesæter LB, Dale H, Schrama JC, Hallan G, Lie SA. Surgical procedures in the treatment of 784 infected THAs reported to the Norwegian Arthroplasty Register. Acta Orthop 2011;82(5):530-7. Crossref 